\title{
Artificial Interphase Layers for Lithium Metal Anode
}

\author{
Jun Guan, Nianwu Li ${ }^{*}$, Le Yu *
}

State Key Lab of Organic-Inorganic Composites, Beijing University of Chemical Technology, Beijing 100029, China.

\begin{abstract}
Lithium (Li) metal is considered as the most promising anode material for high-energy-density batteries owing to its ultra-high theoretical capacity (3860 $\left.\mathrm{mAh} \cdot \mathrm{g}^{-1}\right)$ and the lowest negative electrochemical potential $(-3.040 \mathrm{~V}$ versus standard hydrogen electrode). However, the unstable solid electrolyte interphase (SEI) layers, uncontrollable dendrite growth, and huge volume changes during the plating/stripping processes significantly limit the practical applications of Li metal anodes. Since the unstable SEI layers can promote the nucleation and growth of Li dendrites, they play a crucial role in the decay process of Li metal anodes. The fracture and regeneration of SEI layers continuously consume electrolytes and Li metal anodes during plating/ stripping processes, and the accumulation of SEI layers can increase the interface impedance. Therefore, building artificial interphase layers is one of the most effective strategies to construct a stable SEI, reduce dendrite growth, accommodate large volume changes, and thus obtain excellent cycling performance. In this review, artificial interphase layers have been summarized into three parts based on the conductive properties of interphase, including artificial SEI layers (electronically insulating while ionically conducting), mixed ionic and electronic conductor interphase layers, and nanostructured interphase passivation layers (both ionically and electronically insulating). Artificial SEI layers with high ionic conductivity and low electronic conductivity can be classified into inorganic, organic, and organic/inorganic complex SEI according to the composition of artificial SEI layers. The artificial inorganic SEI layers with a high Young's modulus can suppress the dendrite growth. The artificial organic SEI layers with flexible features can accommodate large interface fluctuations and improve the interphase wettability. The artificial organic/inorganic complex SEI layers with a rigid-flexible structure can restrain dendrite growth and buffer volume change. The mixed ionic and electronic conductor layers possess high ionic conductivity and high Young's modulus, which are beneficial for enhancing the interphase stability and reducing dendrite growth. The artificial alloy mixed conductor layers can improve the Li diffusion coefficient and reduce Li nucleation overpotential, guiding uniform Li plating/stripping. Furthermore, the artificial mixed conductor layers comprising inorganic and organic matter have commendable flexibility and excellent interface compatibility, thereby enhancing the interphase stability and reducing dendrite growth. The nanostructured interphase passivation layers with high chemical stability can deliver Li ion through a confined electrolyte in a uniform porous structure, thereby achieving homogeneous Li plating/stripping. In addition, the structure-effective relationship of artificial interphase layers has been analyzed, and methods for improving the performance of artificial interphase layers, such as physical and chemical stability, ion transportation, interface strength and flexibility, and interfacial compatibility, have been discussed in this review. Finally, we present the main challenge and perspectives of artificial interphase layers.
\end{abstract}

Key Words: Li metal anode; Li metal battery; Artificial interphase; Solid electrolyte interphase; Lithium dendrite

\footnotetext{
Received: September 2, 2020; Revised: September 27, 2020; Accepted: September 28, 2020; Published online: October 19, 2020.

${ }^{*}$ Corresponding authors. Emails: linianwu@mail.buct.edu.cn (N.L.); yule@mail.buct.edu.cn (L.Y.).

The project was supported by the National Natural Science Foundation of China (21975015, 51902016, 21703010), the Fundamental Research Funds for the Central Universities (buctrc201829, buctrc201904), and the Key R\&D Program of Shandong Province (2019TSLH0120).

国家自然科学基金(21975015, 51902016, 21703010), 中央高校基本科研业务专项资金(buctrc201829, buctrc201904)和山东省重点研发计划

(2019TSLH0120)资助项目
}

(C) Editorial office of Acta Physico-Chimica Sinica 


\title{
人工界面层在金属锂负极中的应用
}

\author{
关俊, 李念武, 于乐 ${ }^{*}$ \\ 北京化工大学，有机无机复合国家重点实验室，北京 100029
}

\begin{abstract}
摘要: 金属锂具有极高的比容量 $\left(3860 \mathrm{mAh} \cdot \mathrm{g}^{-1}\right.$ )和最低的电化学反应电位(相对标准氢电位为 $\left.-3.040 \mathrm{~V}\right)$, 被认为是高能量 密度二次电池最具潜力的负极材料。然而金属锂负极界面稳定性差、不可控的枝晶生长、沉积剥离过程中巨大的体积变 化等严重阻碍了金属锂负极的商业化应用。在金属锂表面构建一层物理化学性质稳定的人工界面保护层被认为是解决金 属锂负极界面不稳定和枝晶生长, 缓解体积膨胀带来的界面波动等一系列问题的有效手段。本综述依据界面传导性质, 从离子导通而电子绝缘的人工固态电解质界面(SEI)层、离子/电子混合传导界面、纳米界面钝化层三个部分对人工界面 保护层进行了归纳总结。分析了人工界面保护层的物质结构与性能之间的构效关系, 探讨了如何提高人工界面保护层的 物理化学稳定性、界面离子输运、界面强度与柔韧性、界面兼容性等。最后, 指出用于金属锂负极的人工界面保护层目 前面临的主要挑战, 并对其未来的发展进行了展望。
\end{abstract}

关键词: 金属锂负极; 金属锂电池; 人工界面; 固态电解质界面; 锂枝晶 中图分类号: 0646

\section{1 引言}

随着电动汽车产业和移动电子设备的快速发 展, 人们对储能器件的能量密度不断提出新的期 望和要求 ${ }^{1-4}$ 。然而, 目前广泛应用的高能量密度储 能器件一锂离子电池已经达到 $300 \mathrm{Wh} \cdot \mathrm{kg}^{-1}$, 接近 其理论的极限, 难以满足日益增长的高能量密度 需求 5 。因此, 开发高比容量的材料体系, 发展高 能量密度的新体系电池刻不容缓 6,7 。金属锂因具 有高的理论比容量 $\left(3860 \mathrm{mAh} \cdot \mathrm{g}^{-1}\right)$ 、低的质量密度 $\left(0.59 \mathrm{~g} \cdot \mathrm{cm}^{-3}\right)$ 以及最低的电化学反应电位(相对标 准氢电位 $-3.04 \mathrm{~V})$ 而逐渐受到研究人员的青睐 ${ }^{8-15}$ 。

当金属锂与插层类的过渡金属氧化物材料(如钴 酸锂、三元材料)匹配时, 其能量密度可达 440 $\mathrm{Wh} \cdot \mathrm{kg}^{-1}$; 当用于锂硫 $(\mathrm{Li}-\mathrm{S})$ 和锂氧 $\left(\mathrm{Li}-\mathrm{O}_{2}\right)$ 电池体系 时, 其理论能量密度可进一步增强到 2600 和 3500 $\mathrm{Wh} \cdot \mathrm{kg}^{-1}$ 。因此, 金属锂电池被认为是可代替锂离 子电池的下一代高能量密度电池 ${ }^{16,17}$ 。

然而, 金属锂作为电池负极材料的安全使用 仍面临着巨大挑战。在电池首次充放电过程中, 性 质活泼的金属锂会与电解质反应并在金属锂负极 的表面生成固态电解质界面(SEI)层。SEI层的形成 是一把双刃剑: 一方面, 会消耗金属锂负极和电解
质, 导致电池库伦效率降低; 另一方面, SEI层防 止了金属锂和电解质的直接接触, 一定程度上保 证了金属锂在有机溶剂中的稳定性 ${ }^{18}$ 。电极材料在 循环过程中通常会发生体积膨胀，如石墨负极的 体积膨胀为 $10 \%{ }^{19}$ 。然而, 金属锂负极在循环过程 中的体积膨胀是无限的, 自发生成的SEI层的机械 强度往往较差而不能适应这种持续、巨大的界面 变化, 导致SEI层自身发生断裂, 暴露的新鲜金属 锂会与电解质继续发生反应而生成新的SEI层。随 着金属锂电极反应的进行, SEI层不断的破裂和再 生, 造成了金属锂表面被严重腐蚀、有机溶剂和锂 盐不断被消耗, 电池的库伦效率 $(\mathrm{CE})$ 大幅降低, 最 终导致电解液的干涸和活性物质严重损失, 使电 池失效。另外, SEI层的破裂会引起电解质的锂离 子浓度分布不均, 导致金属锂的不均匀沉积, 从而 产生锂枝晶。锂枝晶高的比表面积导致界面副反 应加剧, 加速了SEI层的破裂和再生。金属锂负极 反应过程中巨大的体积膨胀会产生较大的内应 力, 导致不规则形状的锂枝晶从根部断裂, 变成不 能接受电子的 “死锂”, 失去电化学活性。“死锂” 的不断产生导致锂负极粉化严重, 增加了界面阻 抗, 阻碍了锂离子的扩散以及在电极表面的均匀

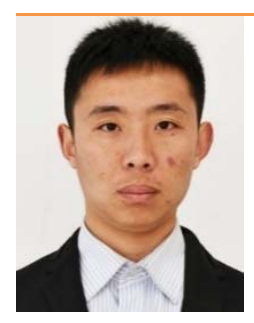

李念武, 南京航空航天大学材料加工工 程专业博士, 现为北京化工大学化工学 院副教授。主要致力于可用于储能器件 的微纳材料设计。

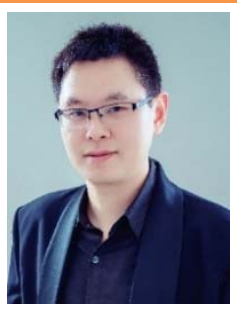

于乐, 新加坡南洋理工大学化学工程专 业博士, 现为北京化工大学有机无机复 合材料国家重点实验室教授。主要致力 于电化学储能与转化微纳材料的界面设 计及合成的研究工作。 
分布, 导致电池失效。此外, 锂枝晶的持续生长会 刺穿隔膜, 造成电池内部正负极短路, 引发胀气、 热失控甚至发生燃烧爆炸等安全事故。

为解决上述难题, 研究人员从金属锂载体设 计、电解质优化、人工界面保护层等多方面来改善 金属锂负极的稳定性和安全性。合理设计亲锂性 载体 ${ }^{20-23}$, 不但能够缓解体积膨胀问题, 还能够诱 导锂离子在集流体上的均匀分布, 从而抑制枝晶 的生长。另外, 高比表面积的三维导电骨架如石墨 烯基体 ${ }^{24,25}$ 、碳纳米管 $(\mathrm{CNT})^{26,27}$ 、三维铜集流体 ${ }^{28,29}$ 等能够有效降低负极表面的局部电流密度, 抑制 枝晶的成核生长。金属锂载体设计难以解决金属 锂和电解质存在副反应的本质问题, 需要借助电 解质优化和人工界面设计来提高界面稳定性。电 解质优化方面, 固态电解质 ${ }^{30-32}$ 具有足够的杨氏模 量来抑制枝晶的生长, 同时解决了传统液态电解 质的易燃、漏液等安全性问题, 但固态电解质与电 极的界面接触不佳, 需要通过界面改性来降低界 面阻抗。有机无机复合电解质、凝胶聚合物电解 质、高浓度锂盐电解质等经过优化后在相对较小 电流密度下可以减少界面副反应、抑制锂枝晶生 长, 继续提高电流密度需要改进界面的锂离子传 导性能和界面稳定性。因此, 人工界面设计成为锂 负极未来发展的关键环节。人工界面设计是通过 纳米技术在金属锂表面构筑一层离子电导率高、 物理化学性质稳定、界面兼容性好、机械强度合适 的人工界面保护层。人工界面层可以有效抑制金 属锂与电解质的副反应, 提高金属锂的沉积/剥离 效率; 界面兼容性调控可以有效降低电解质尤其 是固态电解质与金属锂的界面阻抗, 并提高界面 传导性能; 界面亲锂性等设计可以引导金属锂的 均匀成核生长, 实现金属锂的均匀沉积; 柔韧性好 的界面层可以适应金属锂负极的体积变化, 抑制 枝晶生长。

本综述总结了人工界面层用于金属锂负极的 研究工作, 根据人工界面层的传导性质, 将人工界 面层分成离子导通而电子绝缘的人工SEI层, 离子 和电子混合传导界面层, 纳米结构针化层三类, 总 结了目前人工界面层面临的主要挑战, 展望了人 工界面层的未来发展。

\section{2 人工SEI层}

人工 SEI层具有离子电导率高而且电子绝缘 的特性, 与金属锂和电解质接触稳定, 机械性能良 好, 能够减少界面副反应, 抑制锂枝晶的成核和生 长, 提高金属锂电池的循环寿命, 是最理想的金属
锂界面之一。人工SEI层按照组成可以分为无机物 SEI层、有机聚合物SEI层、有机/无机复合SEI层。

\section{1 无机物人工SEI层}

无机物人工SEI层普遍具有高的杨氏模量可 以抑制锂枝晶的生长。另外, $\mathrm{Li}_{3} \mathrm{PO}_{4} 、 \mathrm{Li}_{3} \mathrm{PS}_{4} 、 \mathrm{Li}_{3} \mathrm{~N}$ 、 $\mathrm{Li}_{2} \mathrm{~S}$ 等快离子导体类人工界面层具有相对较高锂 离子电导率, 能够显著提升界面离子传输能力; 卤 化锂、氧化铝等可以稳定界面, 大幅减少副反应, 提升界面兼容性。

快离子导体类无机人工SEI层可以通过合适 的前驱体与金属锂通过原位反应获得。Guo等 ${ }^{33}$ 将 金属锂浸泡在多聚磷酸(PPA)溶液中, 原位生成了 一层均匀光滑的 $\mathrm{Li}_{3} \mathrm{PO}_{4}$ 基 $\mathrm{SEI}$ 层。如图 $1 \mathrm{a}$ 所示, 普 通金属锂表面的针化层(主要成分为 $\mathrm{LiCO}_{3} 、 \mathrm{LiOH}$ 和 $\mathrm{Li}_{2} \mathrm{O}$ )会自发和电解液发生反应形成SEI层, 在金 属锂表面形成多孔结构, 导致局部锂离子通量的 增加, 进而促进了锂枝晶的成核和生长。当引入了 $\mathrm{Li}_{3} \mathrm{PO}_{4}$ 人工 $\mathrm{SEI}$ 层后, 由于该保护层阻断了金属锂 与电解液之间的副反应, 而且X射线光电子能谱 (XPS) 表明 $\mathrm{Li}_{3} \mathrm{PO}_{4}$ 能够在循环后稳定存在, 避免了 传统SEI层破裂/再修复机制导致的界面不均匀问 题。不仅如此, 该界面保护层具有10-11 GPa的杨 氏模量, 可以有效抑制枝晶的生长。当组装成 $\mathrm{Li} \mid \mathrm{LiFePO}$ 全电池时表现出优良的循环性能, 如图 $1 \mathrm{~b}$, c所示, 全电池循环200圈后, 纯金属锂表面呈 现出 $200 \mu \mathrm{m}$ 的多孔结构 “死锂” 层, 而有 $\mathrm{Li}_{3} \mathrm{PO}_{4} \mathrm{SEI}$ 层保护的金属锂表面仍然保持着光滑致密的结 构。另外, 通过原位反应还可以在金属锂表面生成 $\mathrm{Li}_{2} \mathrm{~S}^{34,35} 、 \mathrm{Li}_{3} \mathrm{PS}_{4}{ }^{36} 、 \mathrm{Li}_{3} \mathrm{~N}^{37-40}$ 等快离子导体人工 SEI层, 大幅提高界面锂离子传递效率, 降低界面 阻抗, 增强界面机械性能, 抑制锂枝晶生长。

卤化锂具有比 $\mathrm{Li}_{2} \mathrm{CO}_{3}$ 更高的表面能和更低的 表面扩散阻力, 可以促进锂离子的均匀沉积, 有效 抑制锂枝晶生长 ${ }^{10}$ 。Cui 等 ${ }^{41}$ 用无毒的商用氟利昂 $\mathrm{R} 134 \mathrm{a}$ 作为反应试剂, 其可以在相对低温条件下反 应生成 $F_{2}, F_{2}$ 继续与金属锂反应生成致密而均匀的 $\mathrm{LiF}$ 涂层。由于 $\mathrm{LiF}$ 具有较强的化学稳定性和机械 强度, 能够有效地阻隔电解质与金属锂的直接接 触, 避免金属锂被腐蚀, 并抑制锂枝晶的形成。当 $\mathrm{LiF}$ 涂布到三维层状 $\mathrm{Li}-$ 还原氧化石墨烯 (Li-rGO) 电极并组装成对称电池时, 在电流密度为 1 $\mathrm{mA} \cdot \mathrm{cm}^{-2}$, 沉积/剥离容量为 $1 \mathrm{mAh} \cdot \mathrm{cm}^{-2}$ 下循环 200 圈后, 仍然无明显的过电位增加; 当组装成锂硫电 池时, 能够有效抑制多硫化物与金属锂的反应, 展 现出良好的循环稳定性。Goodenough等 42 将氟化 石墨 $(\mathrm{GF})$ 粉末与熔融金属锂在高温下进行反应得 


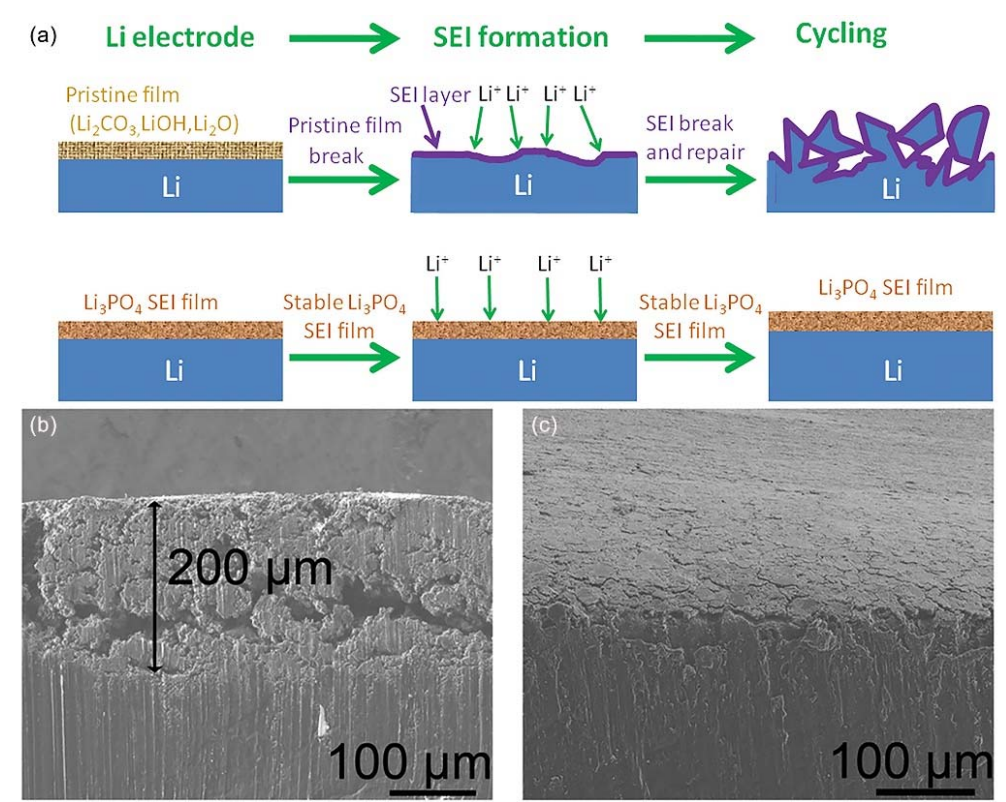

图1 (a) $\mathrm{Li}_{3} \mathrm{PO}_{4}$ 无机保护层的作用示意图; (b)纯 Li在 $\mathrm{LFP}$ 全电池, $0.5 \mathrm{C}$ 循环200圈后的断面形貌;

(c) PPA-Li在LFP全电池，0.5C下循环200圈后的断面形貌 33

Fig. 1 (a) Schematic of $\mathrm{Li}_{3} \mathrm{PO}_{4}$ inorganic protective layer; (b) schematic of pristine lithium morphology after 200 cycles at $0.5 C$ rate in Li|LFP battery system; (c) schematic of PPA-Li morphology after 200 cycles at $0.5 C$ rate in Li|LFP battery system ${ }^{33}$.

Adapted with permission from Ref. 33. Copyright 2015, Wiley-VCH.

到GF-LiF人工SEI层。与纯金属锂相比, 带有GF$\mathrm{LiF}$ 人工 SEI层的电极具有较小的极化电压、更稳 定的循环以及更长的循环寿命。表明该人工GF$\mathrm{LiF}$ 涂层在快速的金属锂沉积/剥离过程中具有更 强的稳定性, 并有效抑制了锂枝晶的生长。不仅如 此, 该保护层还具有良好的空气稳定性。此外, 利 用溶液处理技术 ${ }^{43}$ 、磁控溅射技术 ${ }^{44}$ 等在金属锂表 面制备的LiF类人工SEI层, 同样具有高的界面稳 定性, 减少界面副反应, 抑制锂枝晶的生长。

$\mathrm{Al}_{2} \mathrm{O}_{3}$ 人工 $\mathrm{SEI}$ 层广泛用于改善固态电解质和 金属锂的界面兼容性。 $\mathrm{Hu}$ 等 45 利用原子层沉积技 术 (ALD) 将超薄 $\mathrm{Al}_{2} \mathrm{O}_{3}$ 均匀沉积到金属锂和 $\mathrm{Li}_{7} \mathrm{La}_{2.75} \mathrm{Ca}_{0.25} \mathrm{Zr}_{1.75} \mathrm{Nb}_{0.25} \mathrm{O}_{12}$ (LLCZN) 固态电解质 的界面, $\mathrm{Al}_{2} \mathrm{O}_{3}$ 氧化物涂层有效地改善了金属锂与 LLCZN的润湿性，室温下其界面阻抗从 1710 $\Omega \cdot \mathrm{cm}^{-2}$ 降低到 $1 \Omega \cdot \mathrm{cm}^{-2}$, 而锂化的氧化铝界面有效 地保证了锂离子在金属锂和LLCZN之间的有效传 输, 促进了锂离子在金属锂表面的均匀沉积。此 外, 高杨氏模量的 $\mathrm{Al}_{2} \mathrm{O}_{3}$ 人工 SEI层可以诱导金属 锂均匀成核, 并以逐层的生长方式进行锂沉积, 有 效地促进了锂的均匀沉积。将此 $\mathrm{Al}_{2} \mathrm{O}_{3}$ 薄膜保护的 金属锂组装成为全固态 $\mathrm{Al}_{2} \mathrm{O}_{3} @ \mathrm{Li}|\mathrm{PEO}-\mathrm{LiTFSI}|$ $\mathrm{Al}_{2} \mathrm{O}_{3} @ \mathrm{Li}$ 对称电池, 在电流密度为 $0.1 \mathrm{~mA} \cdot \mathrm{cm}^{-2}$ 、 剥离容量为 $0.1 \mathrm{mAh} \cdot \mathrm{cm}^{-2}$ 的条件下, 可达到 $660 \mathrm{~h}$
的循环寿命。Kozen等 ${ }^{46}$ 利用ALD技术在金属锂表 面沉积一层 $\mathrm{Al}_{2} \mathrm{O}_{3}$ 纳米保护层, 该层有效地保护金 属锂免受空气、硫和有机溶剂的腐蚀。组装成的锂 硫电池经 100 次循环后, 容量仅衰减 $10 \%$, 而纯锂 组装成的电池容量衰减高达 $50 \%$ 。此外, 其他含氧 化合物(如偏钛酸锂、碳酸锂)也能够提高锂离子在 界面处的迁移，促进金属锂的均匀沉积 ${ }^{4}$ 。

无机物人造SEI层通常是具有高离子电导率 和较高模量的刚性物质, 可以有效地促进金属锂 的均匀沉积并抑制枝晶的生长; 但是它们大部分 比较易碎, 在反复的充放电过程中, 往往会发生断 裂, 致使新鲜的金属锂重新暴露在电解质中, 降低 电池的循环性能。因此, 单独的无机物界面保护层 应用受到一定的限制。

\section{2 有机聚合物人工SEI层}

有机聚合物人造界面层通常具有较好的柔韧 性和较高的杨氏模量, 可以有效地缓解并适应金 属锂在循环过程中的体积变化, 因此受到了研究 人员的广泛关注 48 。有机人工 SEI层根据其功能大 致可以分为弹性聚合物SEI层、高杨氏模量聚合物 SEI层、高离子迁移数SEI层等。

高弹性聚合物具有优异的界面适应能力, 能 够通过界面波动来缓解金属锂沉积带来的体积膨 胀, 促进金属锂的均匀沉积。如图2a所示, $\mathrm{Li}^{\text {等 }}{ }^{49}$ 

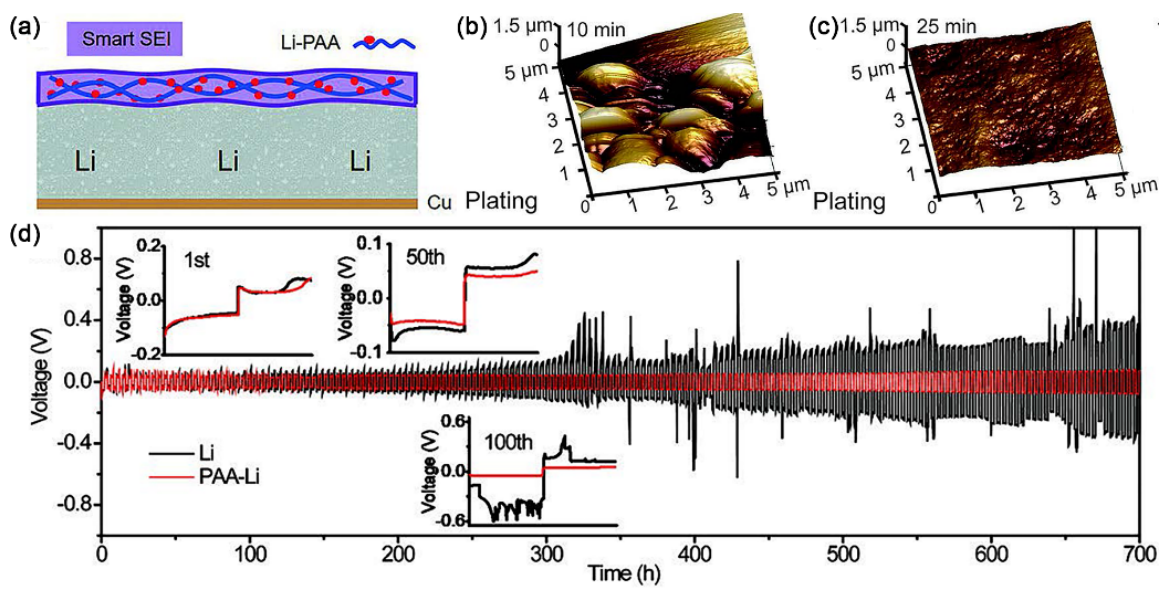

图2 (a) Li-PAA有机聚合物保护层结构示意图; (b)纯Li在 $0.085 \mathrm{~mA} \cdot \mathrm{cm}^{-2}$ 下沉积 $10 \mathrm{~min}$ 后的原位AFM图;

(c) LiPAA-Li负极在 $0.1 \mathrm{~mA} \cdot \mathrm{cm}^{-2}$ 下沉积 $25 \mathrm{~min}$ 后的原位AFM图; (d)对称电池循环性能对比图 49

Fig. 2 (a) Schematic of Li-PAA organic polymer protective layer structure; (b) the AFM image of pristine lithium after plating $10 \mathrm{~min}$ at $0.085 \mathrm{~mA} \mathrm{~cm}^{-2}$; (c) the AFM image of LiPAA-Li after plating $25 \mathrm{~min}$ at $0.1 \mathrm{~mA} \mathrm{~cm}^{-2}$.

(d) comparison of the cycling stability of pristine lithium and LiPAA-Li in a symmetrical cell ${ }^{49}$.

Adapted with permission from Ref. 49. Copyright 2018, Wiley-VCH.

将聚丙烯酸(PAA)的二甲基亚砜(DMSO)溶液滴涂 到金属锂表面，原位生成了具有高弹性的智能 LiPAA聚合物SEI层。LiPAA聚合物具有高度的柔 韧性和结合能力, 可以通过 “自适应界面调节” 来 适应金属锂沉积/剥离过程中的体积变化。如图 $2 b$, c所示, 原位原子力显微镜(AFM)表明纯金属锂在 沉积 $10 \mathrm{~min}$ 后，界面呈现出凸凹不平的沉积形貌， 有大量枝晶结构产生; 而LiPAA-Li电极在沉积 25 $\min$ 后, 其界面波动被有效抑制在了 $100 \mathrm{~nm}$ 内, 实 现了金属锂的均匀沉积。如图2d所示, LiPAA-Li组 装成的对称电池在电流为 $0.5 \mathrm{~mA} \cdot \mathrm{cm}^{-2}$ 下能够循环 长达700 h, 表明LiPAA-Li的电极界面十分稳定。 另外, 金属锂表面上的 “弹性橡皮泥(SP)” 聚合物 SEI层 ${ }^{50}$ 也可以通过动态调节自身的强度限制局部 枝晶的快速生长, 实现金属锂的均匀沉积。

一些特定的聚合物具有高的杨氏模量, 可通 过界面的高机械强度来抑制锂枝晶的生长。 $\mathrm{Hu}^{\text {等 }}{ }^{51}$ 将 $\alpha$-氰基丙烯酸乙酯(ECA)作为聚合单体、 $\mathrm{LiNO}_{3}$ 作 为添加剂溶解到无水丙酮中, 并将该成膜溶液均 匀涂布到金属锂表面, 在金属锂表面的羟基引发 下, ECA发生原位聚合生成PECA聚合物。 $\mathrm{CN}^{-}$和 $\mathrm{NO}_{3}^{-}$能够在循环过程中与金属锂反应生成含氮无 机界面层, 促进了锂离子在电极附近的均匀分布 和快速传导, 并且防止了不良的界面反应; 最外层 柔㓞的PECA聚合物能够适应金属锂在沉积/剥离 过程中的体积变化, 保证了界面的完整性; 该 PECA聚合物层具有 $25 \mathrm{GPa}$ 的高杨氏模量, 有效抑 制了锂枝晶的生长。将此电极组装为LFP全电池时
表现出优异的循环稳定性, 在电流为 $2 C$ 下循环 500 圈后，仍有 $93 \%$ 的容量保持率。

在金属锂电池中, 提高阳离子迁移数, 能够有 效延长 “Sand时间”, 因此, 开发聚合物单离子导 体可有效提高金属锂电池的安全性。Archer等 ${ }^{52}$ 将 离聚物溶液直接浇注在打孔的金属锂表面, 该离 聚物可将锂离子迁移数提高至 0.9 , 直接的可视化 研究表明, 该离聚物SEI层可以使金属锂更均匀地 沉积。在电流密度为 $3 \mathrm{~mA} \cdot \mathrm{cm}^{-2}$ 、沉积/剥离容量为 $3 \mathrm{mAh} \cdot \mathrm{cm}^{-2}$ 的对称电池中, 可达到超过 $800 \mathrm{~h}$ 的稳 定循环。组装成NCA全电池在循环 400 圈后, 其容 量衰减不到 $11 \%$ 。在金属锂的保护中, 不同的有机 聚合物往往具有各自的长处, 所以研究者们常常 利用交联、共聚和枝接等方法将不同种类的聚合 物结合在一起, 达到更加良好的效果。例如: Ma 等 ${ }^{3}$ 将聚 $(3,4$-乙烯二氧噻吩)(PEDOT) 与聚乙二醇 (PEG)的共聚物引入到金属锂表面。该共聚物对金 属锂负极具有很强的粘结性, 可有效抑制锂枝晶 的生长。Gao等 ${ }^{54}$ 合成了一种枝接聚合物 “皮肤”。 该聚合物的环状醚侧链基团具有高度的亲锂性, 有 利于构建均匀、致密和柔韧的SEI; 而多环主链则 具有一定的刚度, 免受其与碳酸酯类电解质发生 过度反应。

部分有机聚合物中含有一些可以诱导锂均匀 沉积的极性基团或原子，因此常常应用到界面保 护层中。Luo等 ${ }^{55}$ 在金属锂表面涂布了一层 $\beta$ 相聚偏 氟乙烯 $(\beta-\mathrm{PVDF})$, 具有电负性的富含 $\mathrm{F}$ 的界面引导 了锂的逐层均匀沉积, 并增强了金属锂电池在高 
电流密度下的循环稳定性。Sun等 ${ }^{56}$ 利用分子层沉 积技术在金属锂表面沉积了一层超薄的 “ 聚腿” 薄 膜。聚艮中丰富的极性基团可以重新均匀地分配 电极表面的锂离子通量, 诱导了锂的均匀沉积。其 它功能性的基团如环状醚 ${ }^{54}$ 、氧乙烯基团 ${ }^{57}$ 、羧酸 58 等也可以诱导离子均匀分布, 实现金属锂的均匀 沉积。

有机聚合物人造SEI层具有较高的柔韧性和 良好的锂离子电导率, 可以与金属锂具有良好的 兼容性, 有效适应电极在循环过程中的体积变化。 但普遍存在不能兼顾离子电导率、界面兼容性和 机械强度的问题。

\section{3 有机/无机复合人工SEI层}

有机/无机复合人工SEI层结合了有机物的柔 韧性和无机物的高离子电导率和机械强度的优 点, 不但可以促进锂离子在电极表面的均匀扩散, 还有效地缓解了电极在循环过程中的界面波动, 二 者协同作用, 有效抑制了锂枝晶的生长, 提高金属 锂电池的循环寿命。根据其组分性质, 有机/无机 复合人工SEI层可以分成无机物快离子导体和有 机物复合人工SEI层、有机物离子导体和无机物复 合人工SEI层、多组分复合人工SEI层。

因石榴石型无机电解质具有与金属锂较好的 稳定性, 较强的刚性以及本身固有的高离子电导 率, 因此可作为复合界面层的无机组分, 与柔韧有 机聚合物结合, 构建理想的复合界面层。Xu等 ${ }^{59}$ 合 成了一种双相单离子传导的人工复合界面层, 其 由刚性的铝掺杂石榴石结构 $\mathrm{Li}_{6.75} \mathrm{La}_{3} \mathrm{Zr}_{1.75} \mathrm{Ta}_{0.25} \mathrm{O}_{12}$ (LLZTO) 无机物作为骨架, 柔软的锂化荎芬 (Nafion)有机物作为填充物构成(记为LLN)。无机 物层能够保持较高的机械刚度和快速的锂离子传 导能力; 而锂化䒺芬层能够赋予界面层较大的弹 性来适应电极的体积变化。如图3a所示, LLN具有 单离子传导特性(锂离子迁移数到达0.82), 有效阻 隔了阴离子的通过, 使得锂离子能够在电极表面 进行均匀而高效的锂离子扩散, 促进了金属锂紧 凑而致密的沉积; 如图 $3 b$ 所示, 当组装为 $\mathrm{Li} \mid \mathrm{Cu}$ 半 电池时, 有 LLN 保护的铜电极与纯铜或只有 LLZTO保护的铜电极相比, 具有更长的循环寿命。 如图3c, d所示, 当对称电池循环 $100 \mathrm{~h}$ 后, 纯金属 锂的侧面可以观察到疏松、多孔的结构, 且有较厚 的 “死锂” 形成; 而受LLN保护的金属锂仍然保持 相对致密的形貌, 证明LLN可有效抑制锂枝晶生 长, 促进金属锂均匀沉积。将此LLN保护的金属锂 与LFP组装成全电池在循环 150 圈后, 仍然有 $87.4 \%$ 的容量保持率。Yang等 ${ }^{60}$ 将 $\mathrm{Li}_{7} \mathrm{La}_{3} \mathrm{Zr}_{1.75} \mathrm{Nb}_{0.25} \mathrm{O}_{12}$
(LLZNO)分散到PEO基电解质中, 在抑制锂枝晶的 同时, 有效地缓解了锂在沉积/剥离过程中的体积 变化。除了典型的石榴石型无机快离子导体外, $\mathrm{Li}_{3} \mathrm{~N}^{61} 、 \mathrm{LiPON}^{62} 、 \mathrm{Li}_{x} \mathrm{SiO}_{y}{ }^{63} 、 \mathrm{LiZrO}_{x}{ }^{64}$ 、 $\mathrm{Li}_{1.5} \mathrm{Al}_{0.5} \mathrm{Ge}_{1.5}\left(\mathrm{PO}_{4}\right)_{3}$ 65等快离子导体也广泛用于有 机/无机复合人工SEI层的制备。

有机物聚合物离子导体和稳定的含锂化合物 如卤化锂的组合广泛用于有机/无机复合人工SEI 层的构筑。 $\mathrm{Xu}$ 等66将聚偏氟乙烯-六氟丙烯(PVDFHFP) 和 LiF共混为复合人工保护层(APL), PVDFHFP基体具有柔软和粘性的特点, 有助于增强界 面层的柔韧性以及与金属锂之间的兼容性, 有效 缓解了电极的界面波动; 刚性的 LiF弓导了锂的均 匀沉积, 抑制了枝晶的生长。将此APL保护的金属 锂和纯金属锂与LFP组装成全电池后, APL保护的 电池寿命可达到普通电池的 2.5 倍。 $\mathrm{Li}^{\text {等 }}{ }^{67}$ 通过浸 渍法在金属锂表面合成了锂化荎芬/ $\mathrm{LiCl}$ 界面 (NLI), 柔软的锂化荎芬提供了快速的离子通道和 良好的界面接触, 而坚固的 $\mathrm{LiCl}$ 盐可增强杨氏模 量, 进而防止严重的界面波动和锂枝晶生长。正由 于NLI的充足的离子电导率和稳定性, 使得 NLI保 护的金属锂电池能够在电流密度为 $8 \mathrm{~mA} \cdot \mathrm{cm}^{-2}$ 的 对称电池中稳定循环 $120 \mathrm{~h}$, 与LTO、LFP组装的全 电池也表现出优异的循环性能。

多组分的有机/无机复合人工SEI层的成分之 间存在协同作用, 受到研究人员的广泛关注。柔软 的有机物基体实现了良好的保形性, 能够有效适 应电极循环过程中的体积波动; 而刚性较强的无 机颗粒的嵌入, 保证了界面层的高离子电导率和 较高的杨氏模量, 有效抑制枝晶的生长 ${ }^{66}$ 。Zhang 等 ${ }^{68}$ 将金属锂在LiTFSI- $\mathrm{LiNO}_{3}-\mathrm{Li}_{2} \mathrm{~S}_{5}$ 三元盐的梄类 电解质中进行预循环, 在金属锂表面电镀了一层 可移植的SEI层, 该 $\mathrm{SEI}$ 层由 $\mathrm{ROCO}_{2} \mathrm{Li}$ 和ROLi ( $\mathrm{R}$ 为 烷基团)有机复合物, 以及 $\mathrm{Li}_{3} \mathrm{~N} 、 \mathrm{Li}_{2} \mathrm{~N}_{x} \mathrm{O}_{y} 、 \mathrm{LiF} 、 \mathrm{Li}_{2} \mathrm{~S}_{x}$ 和 $\mathrm{Li}_{2} \mathrm{~S}_{x} \mathrm{O}_{y}$ 组成的无机复合物构成。无机组分之间 的协同作用使得该层具有较高的离子电导率, 并 有效抑制了锂枝晶生长。将电镀好SEI层的金属锂 用于锂硫电池体系中, 可有效抑制多硫化锂的穿 梭效应。同时, 用于碳酸酯基的 $\mathrm{Li} \mid \mathrm{NCM}$ 全电池时, 依然具有良好的循环性能(始终保持在 $99 \%$ 的库伦 效率)。这也将金属锂在醚类电解质中成膜而被成 功应用到酯类电解质循环中的先例。其它如 $\mathrm{Li}_{2} \mathrm{CO}_{3} 、 \mathrm{LiF}$ 和聚烯复合人工SEI层 ${ }^{69}, \mathrm{LiF} 、 \mathrm{Li}_{3} \mathrm{~N}$ 和 醚类有机物复合人工SEI层等 70 , 也被证明可以大 幅提高金属锂负极的循环性能。

\section{3 人工离子/电子混合传导界面层} 与离子导通电子绝缘的SEI层相比, 人工离子/ 
(a)

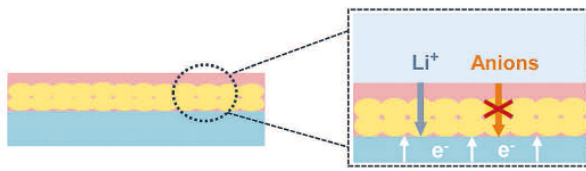

Li plating
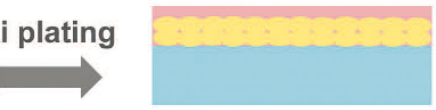

Li metal anode

Rigid LLZTO particle

Elastic Li-Nafion polymer

Liquid electrolyte

(b)

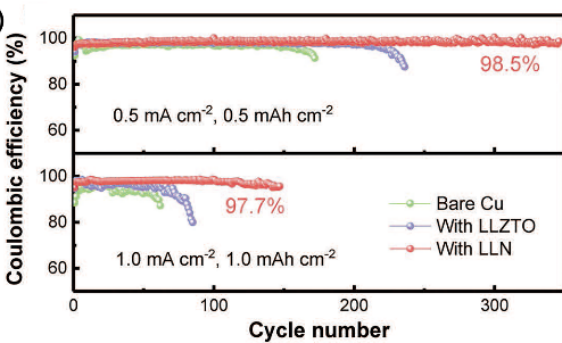

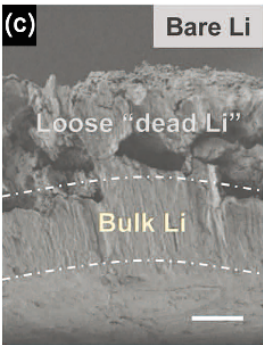

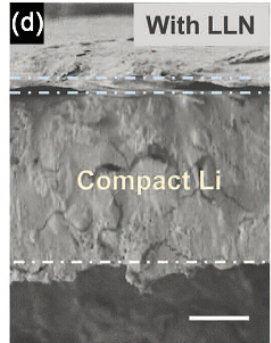

图3 (a) LLN界面层诱导锂均匀沉积示意图; (b) Li|Cu半电池循环性能对比图; (c)纯锂对称电池循环100 hr后的 断面形貌图(标尺为 $20 \mu \mathrm{m}$ ); (d) LLN保护的Li对称电池循环 $100 \mathrm{~h}$ 后的断面形貌图(标尺为 $20 \mu \mathrm{m}$ ) ${ }^{59}$

Fig. 3 (a) Schematic of inducing Li even deposition via LLN interface layer; (b) comparison of the cycling stability in a $\mathrm{Li} \mid \mathrm{Cu}$ cell; (c) side-view scanning electron microscopy (SEM) image of bare $\mathrm{Li}$ after $100 \mathrm{~h}$ cycling, the scale bar of which is 20 $\mu \mathrm{m}$; (d) side-view SEM image of LLN-coated Li after $100 \mathrm{~h}$ cycling, the scale bar of which is $20 \mu \mathrm{m}{ }^{59}$.

Adapted with permission from Ref. 59. Copyright 2019, Wiley-VCH.

电子混合传导界面具有高的离子电导率、较低的 电子传导能力。低的电导率为锂离子在界面层中 的迁移提供迁移电场, 引导锂离子的定向输运, 减 少枝晶结构的产生。根据组分性质, 人工离子/电 子混合传导界面可以分为人工合金界面层和人工 复合物界面层。

\section{1 合金界面层}

大部分金属与金属锂的晶体结构不匹配，金 属锂沉积在上面会有成核过电位。但部分金属(如 $\mathrm{Ag} 、 \mathrm{Au} 、 \mathrm{Mg} 、 \mathrm{Zn}$ 等)在锂金属中具有一定的溶解 度, 在纯锂金属相形成之前, 这些金属会溶解到金 属锂中形成合金相的固溶体表面层, 这些固溶体 表面层与金属锂晶体结构具有较高的匹配度, 为 后续的锂沉积提供缓冲作用, 有效地降低了成核 势垒 ${ }^{11,72}$ 。其它与金属锂可以形成合金的材料(C、 $\mathrm{Sn} 、 \mathrm{Si}$ 等)虽然不能溶解到金属锂中, 其成核过电 位仍小于与金属锂不能形成合金的铜集流体。因 此, 合金材料可以有效降低锂的成核过电位, 并且 提供快速的锂离子传输通道, 能够有效引导金属 锂的均匀沉积, 是一种优良的锂负极界面层。利用 金属锂和金属氯化物 $\left(\mathrm{MCl}_{x}\right)$ 的原位反应也是制备 合金的一种简便方法。其反应式如下 ${ }^{73}$ :

$$
\begin{aligned}
& x \mathrm{Li}+\mathrm{MCl}_{x} \rightarrow \mathrm{M}+x \mathrm{LiCl}(\mathrm{M} \text { 为金属) } \\
& y \mathrm{Li}+z \mathrm{M} \rightarrow \mathrm{Li}_{y} \mathrm{M}_{z}
\end{aligned}
$$

Liang 等 ${ }^{73}$ 用此方法在金属锂表面合成了含有
$\mathrm{LiCl}$ 内部嵌入的 $\mathrm{Li}_{13} \mathrm{In}_{3} 、 \mathrm{LiZn} 、 \mathrm{Li}_{3} \mathrm{Bi}$ 和 $\mathrm{Li}_{3} \mathrm{As}$ 合金。 如图4a所示，合金界面层的上表面被电子绝缘的 $\mathrm{LiCl}$ 完全覆盖，使得锂离子穿过合金层在合金层 的下面沉积, 并且合金层可以为锂离子的输运提 供快速通道，抑制枝晶结构的形成。如图 $4 \mathrm{~b}, \mathrm{c}$ 的 现场原位光学显微镜图显示, 未经过循环的纯金 属锂和有合金层保护的金属锂表面都是光滑平整 的; 在循环 220 圈后, 纯金属锂表面生长了大量疏 松多孔结构的锂枝晶和 “死锂”, 而有合金层保护 的金属锂表面却依然保持光滑平坦的形貌，证明 该合金层有效抑制了枝晶生长，减少 “死锂” 的产 生。当与 $\mathrm{LTO}$ 组装为全电池时, 在电流密度为 $5 C$ 条 件下，纯金属锂负极循环600圈后就坏掉，而合金 层保护的电极在循环 1500 圈后，仍然没有明显的 容量衰减。相似地, Jiang 等 ${ }^{74}$ 用质量分数为 $1 \%$ 环 氧丙烷 $(\mathrm{PO})$ 的 $\mathrm{SnCl}_{4}$ 的 $\mathrm{THF}$ 溶液浸泡金属锂, 合成 了 $\mathrm{Li}-\mathrm{Sn}$ 合金。生成的 $\mathrm{LiCl}$ 和 $\mathrm{SnCl}_{4}$ 引发了 $\mathrm{PO}$ 和 $\mathrm{THF}$ 的开环聚合, 提高了界面层的亲锂性, 有效地增加 了金属锂在潮湿空气中的稳定性。另外 $\mathrm{LiAl}^{75}$ 、 $\mathrm{LiSi}^{76} 、 \mathrm{LiPb}^{77}$ 等合金在金属锂表面被设计制备出 来, 研究表明这些合金人工界面层可以促进金属 锂的均匀沉积。

$\mathrm{Au} 、 \mathrm{Ag} 、 \mathrm{Zn}$ 或 $\mathrm{Mg}$ 能够与金属锂形成固溶体缓 冲层, 降低金属锂沉积的过电位, 为锂沉积提供均 匀的成核位点, 减少枝晶结构的生成 ${ }^{48}$ 。 $\mathrm{Liu}$ 等 ${ }^{78}$ 通 


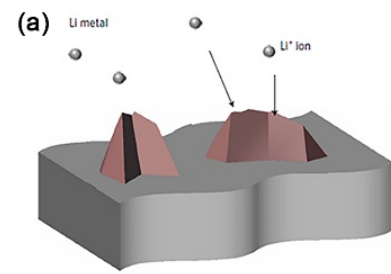

(d) Poor Li wetting

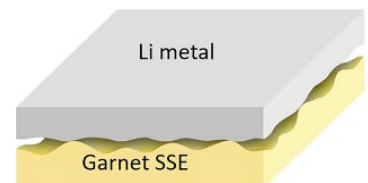

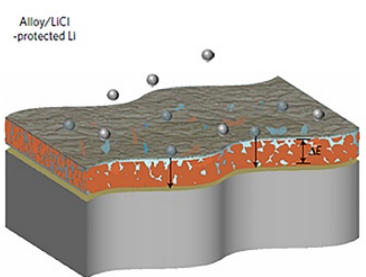

Good Li wetting

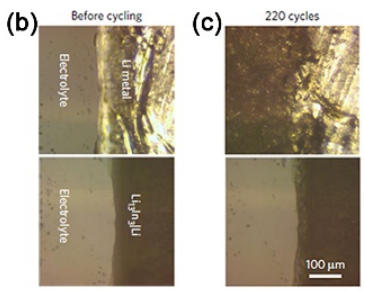

(e)

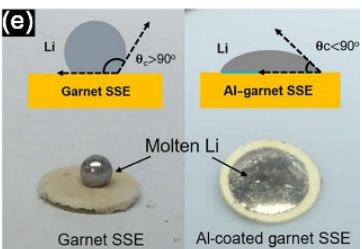

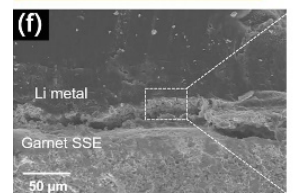
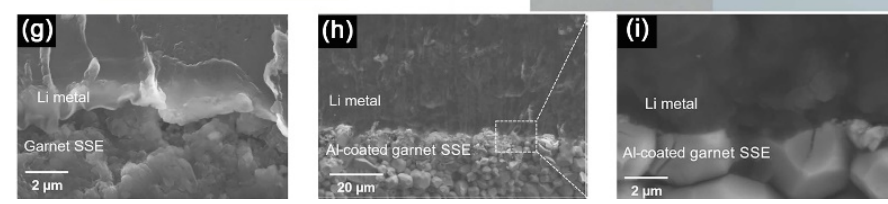

图4 (a)金属氯化物 $\mathrm{MCl}_{x}(\mathrm{M}=\mathrm{In}, \mathrm{Zn}, \mathrm{Bi}, \mathrm{As})$ 保护层的作用示意图; (b)纯金属锂和 $\mathrm{Li}_{13} \mathrm{In}_{3} \mid \mathrm{Li}$ 对称电池在循环前的 断面形貌对比图(其标尺与(c)图一致); (c)纯金属锂和 $\mathrm{Li}_{13} \mathbf{I n}_{3} \mid \mathbf{L}$ i对称电池在循环220圈后的断面形貌对比图; (d) Li-Al合金 改善金属锂与石榴石固态电解质之间的润湿性示意图; (e)纯金属锂、Li-AI合金保护的金属锂与石榴石固态电解质之间的

润湿效果对比图; (f)纯金属锂与石榴石固态电解质的界面形貌图; (g)局部放大的纯金属锂与石榴石固态电解质的 界面形貌图; (h) Li-Al合金保护的金属锂与石榴石固态电解质的界面形貌图; (i)局部放大的Li-Al合金保护的金属锂与 石榴石固态电解质的界面形貌图 79

Fig. 4 (a) Schematic of Li deposition on the bare $\mathrm{Li}$ and $\mathrm{MCl}_{x}(\mathrm{M}=\mathrm{In}, \mathrm{Zn}, \mathrm{Bi}$, As) protected $\mathrm{Li}$; (b) comparison of the side-

view SEM before cycling between bare $L i$ and $\mathrm{Li}_{13} \mathrm{In}_{3} \mid \mathrm{Li}$ in a symmetric cell (the scale bar is consistent with picture c);

(c) comparison of the side-view SEM after cycling 220 cycles between bare $L i$ and $\mathrm{Li}_{13} \mathrm{In}_{3} \mid \mathrm{Li}$ in a symmetric cell; (d) schematic of improving wettability between $\mathrm{Li}$ and garnet SSE via $\mathrm{Li}$-Al alloy; (e) comparison of interfacial wettability between $\mathrm{Li}$ and garnet SSE in pristine lithium and Li-Al alloy; (f) the side-view SEM of interfacial morphology between pristine Li and garnet SSE; (g) locally amplified side-view SEM of interfacial morphology between pristine Li and garnet SSE; (h) the side-view SEM of interfacial morphology between Li-Al alloy protected Li and garnet SSE; (i) locally amplified side-view SEM of interfacial morphology between $\mathrm{Li}-\mathrm{Al}$ alloy protected $\mathrm{Li}$ and garnet SSE ${ }^{79}$. (a-c) Adapted from Ref. 73. Copyright 2017, Springer Nature; (d-i) Adapted from Ref. 79. Copyright 2017, AAAS.

过磁控溅射技术将 $\mathrm{Cu}_{99} \mathrm{Zn}$ 均匀地沉积到铜基体表 面, Zn与 $\mathrm{Li}$ 形成固溶体, 为金属锂提供了均匀的成 核位点。正因为锂的成核得到了均匀的控制，所以 其在 $\mathrm{Li} \mid \mathrm{Li}$ 对称电池中, 在电流密度为 $0.5 \mathrm{~mA} \cdot \mathrm{cm}^{-2}$ 、 沉积/剥离容量为 $0.5 \mathrm{mAh} \cdot \mathrm{cm}^{-2}$ 下循环 $1000 \mathrm{~h}$ 后, 仍 然能够保持较小且稳定的过电位。

不仅如此, 合金人工SEI层也常常被用在固态 电解质中, 来改善金属锂与固态电解质之间的界 面接触。如图 $4 \mathrm{~d}$ 所示, 石榴石型固态电解质与金属 锂之间的接触性不佳, 会导致二者之间存在较大 的界面阻抗和不均匀的电流分布。所以 $\mathrm{Fu}$ 等 ${ }^{79}$ 在金 属锂和 $\mathrm{Li}_{7} \mathrm{La}_{2.75} \mathrm{Ca}_{0.25} \mathrm{Zr}_{1.75} \mathrm{Nb}_{0.25} \mathrm{O}_{12}$ (LLCZN) 的界 面引入了一层 $\mathrm{Li}-\mathrm{Al}$ 合金。如图 $4 \mathrm{e}$ 所示, 该层合金 有效地提高了金属锂在LLCZN表面的润湿性。如 图4f，g，在没有合金层保护的界面上，可以看到 金属锂与LLCZN之间具有较大的缝隙, 只有局部
的点接触, 这极大增加了界面阻抗; 而图 $4 \mathrm{~h}, \mathrm{i}$ 反 映了熔融的金属锂已经填入进石榴石颗粒的孔道 和晶界中, 增加了金属锂和固态电解质之间的接 触面积。正是由于亲锂层的存在, 室温下锂与 LLCZN 的界面阻抗从 $950 \Omega \cdot \mathrm{cm}^{-2}$ 降为了 75 $\Omega \cdot \mathrm{cm}^{-2}$ 。

\section{2 人工复合物混合传导界面层}

相比于单独的合金层，复合物混合界面层往 往由高离子电导率物质和良好电子电导物质复合 而成，或者两种及以上的物质复合在一起产生协 同作用从而具有高的离子电导率和一定的电子电 导。另外, 某些复合物传导界面层的两种物质是刚 性和柔性物质的组合, 使得混合传导界面层具有 刚柔并济的特点。

用于液态金属锂电池的复合物混合传导界面 层一般具有高的杨氏模量。 $\mathrm{Yan}$ 等 ${ }^{80}$ 将 $\mathrm{CuF}_{2}$ 和 
$\mathrm{LiNO}_{3}$ 共同溶解在DME中, 并将其直接滴涂到金 属锂表面, $\mathrm{CuF}_{2}$ 和金属锂发生取代反应, 形成了 $\mathrm{LiF} / \mathrm{Cu}$ 离子/电子混合导体界面(MCI)。如图5a所 示, 通过 $\mathrm{Cu}$ 原子的引入, 实现了在 $\mathrm{LiF} / \mathrm{Cu}$ 晶界区的 优先储锂, 与单独富含 $\mathrm{LiF}$ 的SEI层相比, 具有更高 的离子电导率。MCI的高杨氏模量与快速离子传 输特性共同抑制了枝晶的生长。如图 $5 b$ 所示, 该 $\mathrm{LiF} / \mathrm{Cu} \mathrm{MCI}$ 具有 $12.9 \mathrm{GPa}$ 的高杨氏模量, 远高于传 统SEI的 $0.63 \mathrm{GPa}$ 的杨氏模量, 有效抑制了枝晶的 生长。在图 $5 \mathrm{c}$ 的对称电池中, 有 $\mathrm{MCI}$ 保护的锂负极 在运行 2000 圈后, 依然保持在 $80 \mathrm{mV}$ 的稳定过电 位, 而纯金属锂在运行900圈后就坏掉了。传统的 人工界面层设计(如涂布或溅射)往往受到试剂或 惰性环境的限制而不能够得到充分施展。Zhang 等 81 通过连续的辊压, 将 $3 \mu \mathrm{m}$ 厚的碳层枝接到 50 $\mu \mathrm{m}$ 的锂箔上, 合成了三明治形状的金属锂负极。 由于碳层为锂沉积提供了丰富的成核位点, 促进 了锂的均匀沉积/剥离。因此, 制备的三明治状 $\mathrm{Li} / \mathrm{C}$ 复合电极在 $\mathrm{Li} \mid \mathrm{LFP}$ 全电池和 $\mathrm{Li} \mid \mathrm{S}$ 电池中展现了优 异的循环稳定性。Cui等 ${ }^{82}$ 在铜基体表面合成了无 定型的空心纳米碳球薄膜, 空心纳米碳球层与铜 集流体具有较弱的结合, 使得薄膜能够在循环过 程中, 自由地上下移动来适应沉积/剥离过程中电 极的体积变化, 该层薄膜具有 $200 \mathrm{GPa}$ 的较大杨氏 模量, 有效抑制了枝晶的生长。正是由于其良好的 柔韧性和机械强度, 使得其具有良好的电化学性 能。将纯金属锂作为对电极, 与该薄膜覆盖的铜集
流体组装成半电池时, 在电流密度为 $0.25 \mathrm{~mA} \cdot \mathrm{cm}^{-2}$ 下循环 150 圈后, 仍然保持 $99 \%$ 的库伦效率。Yan等 83 用甲苯引发了 $\mathrm{Li}_{0.35} \mathrm{La}_{0.52}[\mathrm{~V}]_{0.13} \mathrm{TiO}_{3}$ (LLTO) 与金属锂 之间发生反应，使得LLTO具有了电子导通特性。 合成的混合离子电子传导界面有助于缓和锂离子 浓度梯度并调整二次电流的均匀分布。当用于金 属锂电池时, 可有效阻止电解质对金属锂的侵蚀, 并抑制枝晶的生长。当用于锂硫电池体系时, 在电 流密度为 $3 \mathrm{~mA} \cdot \mathrm{cm}^{-2}$ 下循环 200 圈后, 仍能保持大 于 $98 \%$ 的库伦效率和大于 $700 \mathrm{mAh} \cdot \mathrm{g}^{-1}$ 的比容量。

将复合物界面层用于固态电解质中, 可有效 改善电解质和电极之间的离子电导率、提高界面 处的机械强度, 同时还可以改善金属锂与固态电 解质之间的润湿性。如图6a所示, 固态聚合物电解 质因较低的离子电导率而不能够有效调控锂离子 的均匀分布, 而且较差的机械强度会导致其难以 抑制枝晶生长。如图 $6 \mathrm{~b}$ 所示, Yan等 ${ }^{84}$ 将PEO均匀 涂布在无机 $\mathrm{Mg}_{3} \mathrm{~N}_{2}$ 层上(PEO- $\mathrm{Mg}_{3} \mathrm{~N}_{2}$ ), 经电化学循 环后, $\mathrm{Mg}_{3} \mathrm{~N}_{2}$ 与 $\mathrm{Li}$ 金属原位反应生成 $\mathrm{Li}_{3} \mathrm{~N}$ 和 $\mathrm{Mg}$ 金 属; 其中 $\mathrm{Li}_{3} \mathrm{~N}$ 具有较高的离子电导率, 降低了锂离 子的浓度梯度; 而 $\mathrm{Mg}$ 金属促进了循环过程中电流 密度的均匀分布。如图6c、d所示, AFM表明PEO$\mathrm{Mg}_{3} \mathrm{~N}_{2}$ 保护的锂负极表面更光滑, 电流分布也更加 均匀。组装成对称电池时, 如图6e所示, PEO$\mathrm{Mg}_{3} \mathrm{~N}_{2}$ 保护的锂负极在循环 $1500 \mathrm{~h}$ 后仍然稳定, 而 纯金属负极的过电位在 $400 \mathrm{~h}$ 后就开始急剧增加。 说明PEO- $\mathrm{Mg}_{3} \mathrm{~N}_{2}$ 界面保护层能够有效平衡电极表 (a)

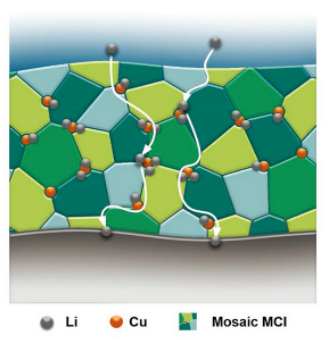

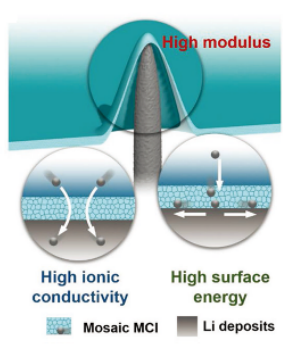

(b)

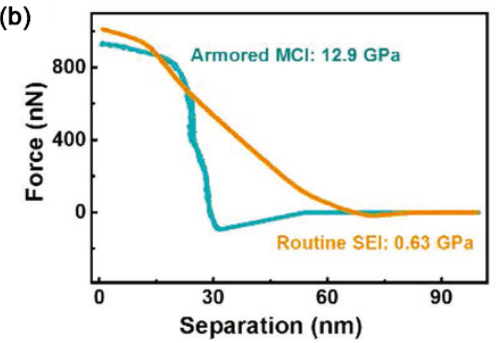

(c)

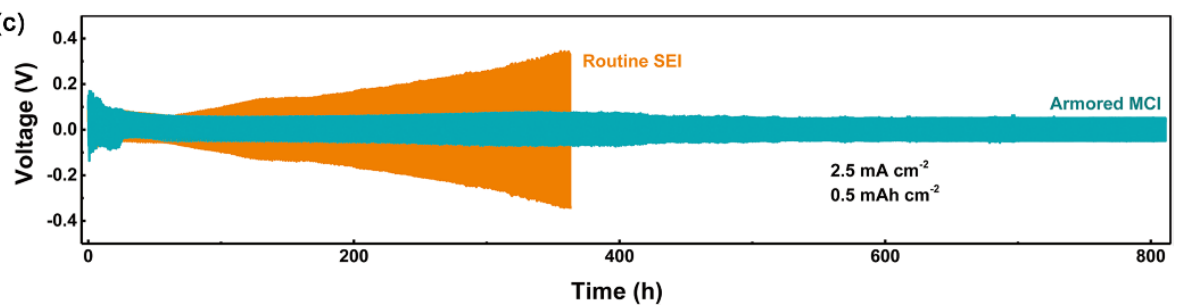

图5 (a) LiF/Cu MCI调控锂沉积作用示意图; (b) LiF/Cu MCI与常规SEI的机械模量对比图;

(c) $\mathrm{LiF} / \mathrm{Cu} \mathrm{MCI}$ 与常规SEI在对称电池循环性能中的对比图 ${ }^{80}$

Fig. 5 (a) Schematic of inducing Li deposition via LiF/Cu MCI; (b) comparison of routine SEI with LiF/Cu MCI in mechanical modulus; (c) comparison of $\mathrm{LiF} / \mathrm{Cu} \mathrm{MCI}$ with routine SEI in cycling performance of a symmetric cell ${ }^{80}$. 
(a)

(b)
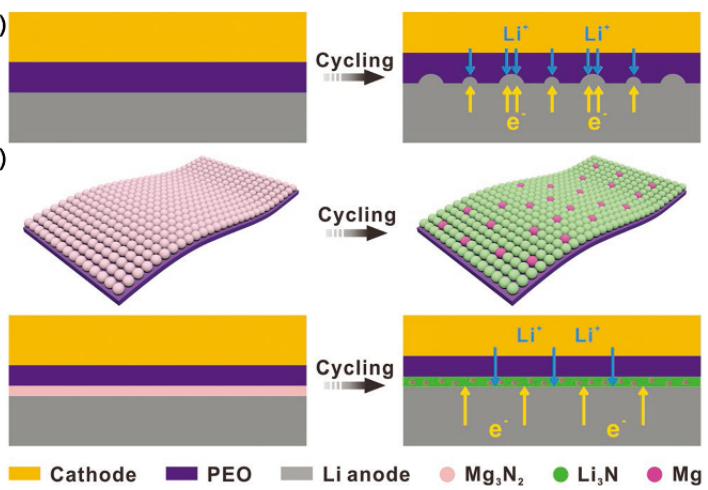

(c) -0.13

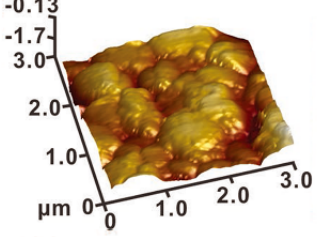

(d)

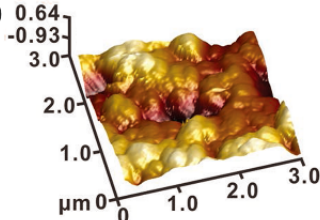

(e)

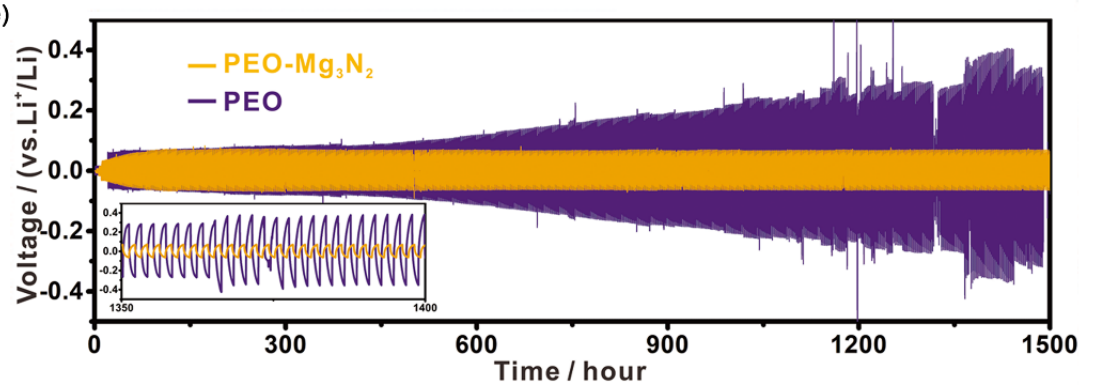

图6 (a) PEO电解质的锂沉积行为示意图; (b) PEO- $\mathrm{Mg}_{3} \mathrm{~N}_{2}$ 电解质的演化过程示意图;

(c) PEO-Mg $3 \mathrm{~N}_{2}$ 电解质循环后的AFM图; (d) PEO电解质循环后的AFM图; (e)对称电池循环性能对比 ${ }^{84}$

Fig. 6 (a) Schematic of Li deposition behavior in PEO electrolyte; (b) schematic of the evolutionary processes of PEO-

$\mathrm{Mg}_{3} \mathrm{~N}_{2}$ electrolyte; (c) the AFM images of lithium with PEO-Mg $\mathbf{N}_{2}$ electrolyte after cycling; (d) the AFM images of lithium with PEO electrolyte; (e) comparison of cycling performance between PEO electrolyte and PEO-Mg $\mathrm{Mg}_{2}$ electrolyte $^{84}$.

Adapted with permission from Ref. 84. Copyright 2019, Wiley-VCH.

面的电流密度, 促进锂的均匀沉积/剥离。Huo等 85 利用磁控溅射技术，在LLZTO表面均匀沉积了一 层 $\mathrm{Cu}_{3} \mathrm{~N}$ 薄膜, 该薄膜经 $200{ }^{\circ} \mathrm{C}$ 高温与熔融锂发生 反应，生成了 $\mathrm{Cu} / \mathrm{Li}_{3} \mathrm{~N}$ 混合离子/电子导体层 $\left(\mathrm{Cu} / \mathrm{Li}_{3} \mathrm{~N} \mathrm{MCL}\right)$, 该层有效改善了金属锂与LLZTO 之间的润湿性, 使得界面阻抗从单一相 (LLZTO/Li) 的 $1138.5 \Omega \cdot \mathrm{cm}^{-2}$ 降低到有 MCL保护 (LLZTO-MCL/Li) 的 $83.4 \Omega \cdot \mathrm{cm}^{-2}$ 。将 LLZTO$\mathrm{MCL} / \mathrm{Li}$ 与 $\mathrm{LCO}$ 组装成全电池, 在电流为 $0.2 C$ 下循 环 300 圈后, 仍然有 $81.1 \%$ 的容量保持率。

\section{4 人工纳米结构界面针化层}

此类材料本身电子和离子传导能力都比较 差, 但是能够通过自身纳米结构中的电解质来传 递锂离子, 因此常可以作为人工界面钝化层来改 善锂的沉积行为。人工纳米结构界面针化层的组 成可以分成多孔有机物界面钝化层和多孔无机物 界面针化层。

本征微孔聚合物(PIM) 是一种带有丰富微孔 的聚合物, 其微孔均匀分布在聚合物基体中, 为锂 离子的扩散构建了各向同性的通道网络; 带有弯 曲螺旋中心的骨架展现了高度的刚性和柔韧性, 成
为理想人工界面针化层的候选者之一。如图 $7 \mathrm{a}$ 所 示, Yang 等 ${ }^{86}$ 在锂䈃和铜䈃表面均匀涂覆了一层 PIM-1, 该层能够将溶剂和大的阴离子固定在其内 部的网络和微孔中, 为锂离子的扩散和输运提供 了媒介。均匀分布的、各向同性的孔道网络确保了 电极表面分布均匀的锂离子通量, 因此促进了锂 的均匀沉积。当该薄膜涂布在金属锂表面时, 可有 效防止氧气和水的侵蚀。如图 7b、c所示, 没有PIM1 保护的金属锂在空气中暴露 2 周后, 颜色明显变 黑, 证明已发生氧化; 而有PIM-1保护的金属锂颜 色(如图7e、f)只是加深了一点, 证明一定程度上保 护了金属锂负极。扫描电子显微镜用于表征此 PIM-1保护的锂沉积行为, 如图7d所示, 没有PIM1 保护的锂在铜簿上沉积出现了大量松散多孔的 锂枝晶; 而图 $7 \mathrm{~g}$ 可隐隐约约观测到金属锂沉积到 PIM-1的下方, 表现出了稳定和均匀的界面, 证明 在PIM-1的保护下, 金属锂得以均匀沉积在电极表 面。将PIM-1保护的金属锂与 LFP组装成全电池 时, 在电流为 $1 C$ 下循环 600 圈后，仍然有 $80 \%$ 的容 量保持率, 十分有商用化的潜力。人造界面钝化层 也经常被用在锂硫电池中，在抑制枝晶生长的同 时，抑制多硫化物与金属锂之间发生副反应。 
(a)

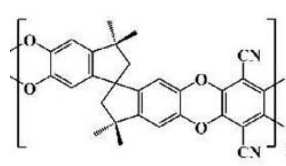

PIM-1

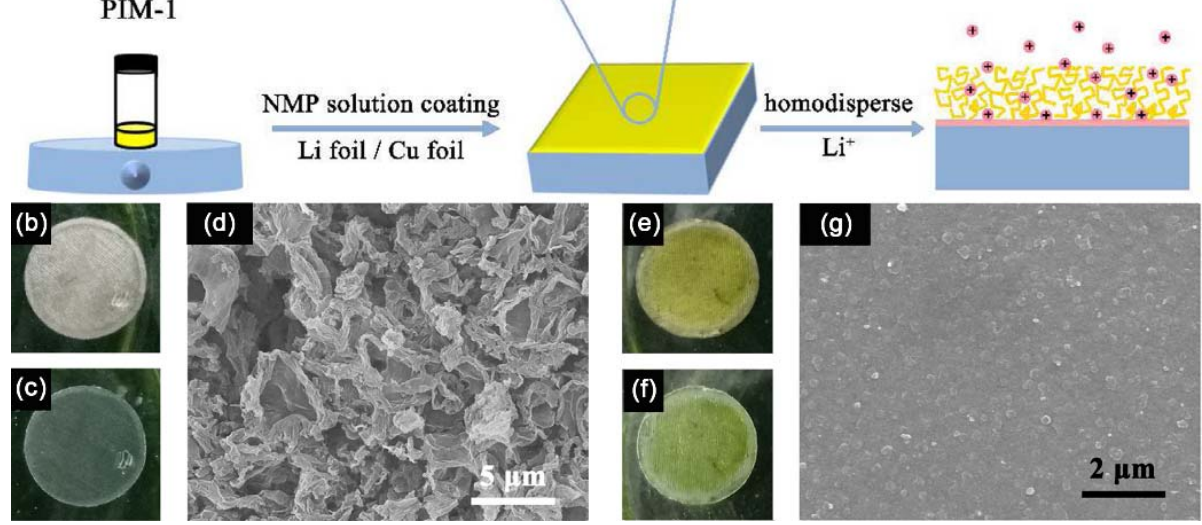

图7 (a) PIM-1膜在 $\mathrm{Cu} / \mathrm{Li}$ 箔表面的制备过程示意图; 纯金属锂在铜箔表面的沉积并在空气中分别暴露(b) $0 \mathrm{~h}$ 后,

(c) 2周后的光学图片, (d)金属锂在铜箔表面的沉积形貌图; Li@PIM-1电极在空气中分别暴露(e) 0 h后,

(f) 2周后的光学图片; (g)金属锂在Cu@PIM-1表面的沉积形貌图 ${ }^{86}$

Fig. 7 (a) Schematic of the fabrication of the PIM-1 membrane on $\mathrm{Cu} / \mathrm{Li}$ foil; optical photographs of Li electrode

(b) after $\mathrm{O}$ h and (c) 2 weeks in air; (d) SEM image of Li deposition on Cu foil; Li@PIM-1 electrode (e) after 0 h and (f) 2 weeks in air; (g) SEM image of Li deposition on Cu@PIM-1 ${ }^{86}$.

Adapted from Ref. 86. Copyright 2019, Elsevier.

聚二甲基硅氧烷(PDMS)因化学性质稳定、加 工方便而常被用于界面针化层的制备。PDMS本身 并不是一种锂离子导体, Zhu等 ${ }^{87}$ 采取氢氟酸 $(\mathrm{HF})$ 刻蚀的方法, 人为地在PDMS膜中制造出纳米孔来 提供锂离子输运的途径, 通过控制酸刻蚀时间, 有 效控制了孔径大小, 进而改变PDMS对锂离子输运 和沉积行为的影响。在锂铜半电池测试中, 有 PDMS保护的铜电极与普通的铜电极相比, 在循环 中具有更高的库伦效率和循环寿命 (如在电流为 1 $\mathrm{mA} \cdot \mathrm{cm}^{-2}$ 、沉积/剥离容量为 $1 \mathrm{mAh} \cdot \mathrm{cm}^{-2}$ 下循环 100 圈后, 有PDMS保护的半电池仍然有 $90 \%$ 以上的库 伦效率, 而普通的半电池在 30 圈后, 就降到了 $20 \%)$ 。 $\mathrm{Li}_{\text {等 }}^{88}$ 直接将金属锂浸泡在含 PDMS 的 DOL/DME溶液中, 然后蒸发掉溶剂, 得到PDMS 保护的金属锂负极。该保护层不仅能够稳定负极 界面, 还能够抑制锂枝晶的生长, 在锂硫电池中有 效地抑制了多硫化物的穿梭效应。

另外, 多孔有机纳米针化层中的有机物的官 能团和孔结构都可以在一定程度上进行调控，有 利于金属锂的均匀沉积/剥离。Luo等 ${ }^{89}$ 在负极表面 涂布了Nafion/PVDF混合涂层, Nafion可以有效抑 制多硫化物的穿梭效应, 但是其在电解质中易于 膨胀并溶解到电解质中, 导致其不能够完全覆盖
到电极表面。加入PVDF后, 可有效防止Nafion的 膨胀, 进而抑制多硫化物的穿梭效应, 大大减轻了 锂硫电池的自放电。不仅如此, Nafion中- $\mathrm{SO}_{3}^{2-}$ 和 PVDF骨架独特的介电性质促进了锂离子在负极 表面的均匀再分布, 因此缓解了枝晶的形成。Yao 等 ${ }^{90}$ 通过溶剂蒸发辅助自组装的方式在金属锂表 面涂布了一层二维还原氧化石墨烯(2D rGO), 在 锂化/脱锂过程中, rGO会破裂成马赛克形状的片, 在片与片之间的缝隙中为锂的存储提供充足的空 间。锂化 $\mathrm{rGO}$ 和金属锂之间的高亲和力促进了快速 而均匀的锂沉积, 保证了其在锂离子电池和锂硫 电池中的优良电化学性能。无机物纳米结构针化 层主要是一些离子、电子绝缘并且与金属锂接触 比较稳定的纳米结构针化层。Jing等 ${ }^{91}$ 通过旋涂法 在锂负极表面覆盖了一层多孔结构的 $\mathrm{Al}_{2} \mathrm{O}_{3}$ 保护 层, 该保护层能够为锂离子输运和电解质的渗透 提供充足的空间, 同时还有效阻隔了金属锂和多 硫化锂的直接接触，避免了金属锂的腐蚀。

\section{5 总结与展望}

金属锂被认为是实现下一代高能量密度储能 器件的首选负极材料, 其与 $\mathrm{O}_{2} 、 \mathrm{~S}$ 组成的高比能量 密度锂氧电池和锂硫电池具有巨大的应用潜力。由 
于金属锂本身极具活泼性, 所以其在接触电解质 过程中会发生氧化还原反应, 在二者界面生成 SEI 层。由于金属锂在沉积/剥离过程中面临着无限的 体积膨胀和锂枝晶生长的问题, 所以在其循环过 程中SEI层会发生不断的断裂和再修复, 持续消耗 着电解液, 最终导致电池失效。即使是在固态电解 质中, 锂枝晶的生长问题也没有得到根本的解决。 所以, 设计人工界面保护层来取代或保护本源的 SEI层, 是一种有效的抑制枝晶生长、缓解体积变 化带来的界面波动的策略。

针对金属锂负极面临的挑战, 本文总结了人 工界面保护层对锂负极的保护策略。这些策略从 力学设计(提高机械强度来抑制枝晶生长, 改善柔 㓞性以缓解体积变化带来的界面波动) 、化学作用 (调控界面官能团提供均匀的成核位点、为集流体 提供较强的亲锂性、改善界面润湿性来诱导锂均 匀沉积)、物理化学参数及结构改进 (高锂离子迁移 系数、高离子电导率、多孔结构)等多角度提高了 金属锂电池的电化学性能。

目前人工界面保护层已经取得了令人瞩目的 成就, 但是人工界面保护层的未来发展仍需要面 临一系列的挑战。首先, 锂离子在人工界面层处扩 散、迁移、被还原的过程及相应的机理等基础科学 问题需要借助先进的原位表征手段及恰当的模拟 计算进行深层次的研究, 为未来人工界面层的发 展提供理论基础。其次, 综合考虑人工界面保护层 的物理化学稳定性、界面锂离子的输运、界面的机 械强度及柔韧性、界面与金属锂和电解质的兼容 性等关键因素, 对人工界面层进行合理的精准调 控设计是未来发展的必经之路。最后, 目前实验室 用于研究的电流密度和金属锂的面容量分别在 3 $\mathrm{mA} \cdot \mathrm{cm}^{-2}$ 和 $3 \mathrm{mAh} \cdot \mathrm{cm}^{-2}$, 未来至少需要逐步提高到 $10 \mathrm{~mA} \cdot \mathrm{cm}^{-2}$ 和 $10 \mathrm{mAh} \cdot \mathrm{cm}^{-2}$ 的级别, 并且充分考虑 成本及制备方法的工业可行性, 进一步推进金属 锂电池的商业化应用。

虽然人工界面保护层未来的发展面临着诸多 挑战, 但是随着各种先进原位表征、现场电化学等 手段的开发和应用, 表界面化学的发展, 材料科学 及纳米技术的进步, 一系列的挑战和难题会被逐 步解决。人工界面保护层未来的突破与发展会促 进高能量密度金属锂电池的商业化应用, 推动新 能源领域的技术革命。

\section{References}

(1) Dunn, B.; Kamath, H.; Tarascon, J. M. Science 2011, 334, 928. doi: $10.1126 /$ science. 1212741
(2) Grande, L.; Paillard, E.; Hassoun, J.; Park, J. B.; Lee, Y. J.; Sun, Y. K.; Passerini, S.; Scrosati, B. Adv. Mater. 2015, 27, 784. doi: 10.1002/adma.201403064

(3) Lu, Y.; Tikekar, M.; Mohanty, R.; Hendrickson, K.; Ma, L.; Archer, L. A. Adv. Energy Mater. 2015, 5, 1402073.

doi: 10.1002/aenm.201402073

(4) Yang, P.; Tarascon, J. M. Nat. Mater. 2012, 11, 560. doi: 10.1038/nmat3367

(5) Li, S.; Jiang, M.; Xie, Y.; Xu, H.; Jia, J.; Li, J. Adv. Mater. 2018, 30 , 1706375. doi: 10.1002/adma.201706375

(6) Choi, J. W.; Aurbach, D. Nat. Rev. Mater. 2016, 1, 16013. doi: $10.1038 /$ natrevmats.2016.13

(7) Goodenough, J. B.; Kim, Y. Chem. Mater. 2010, $22,587$. doi: $10.1021 / \mathrm{cm} 901452 \mathrm{z}$

(8) Li, H. P.; Ji, X. Y.; Liang, J. J. Rare Met. 2020, 39, 861. doi: 10.1007/s12598-020-01456-8

(9) Zhang, F.; Shen, F.; Fan, Z. Y.; Ji, X.; Zhao, B.; Sun, Z. T.; Xuan, Y. Y.; Han, X. G. Rare Met. 2018, 37, 510. doi: 10.1007/s12598-018-1054-6

(10) Cheng, X. B.; Zhang, R.; Zhao, C. Z.; Zhang, Q. Chem. Rev. 2017, 117, 10403. doi: 10.1021/acs.chemrev.7b00115

(11) Cheng, X. B.; Zhang, Q. J. Mater. Chem. A 2015, 3, 7207. doi: $10.1039 / \mathrm{c} 5 \mathrm{ta} 00689 \mathrm{a}$

(12) Wang, M. Q.; Peng, Z.; Lin, H.; Li, Z. D.; Liu, J.; Ren, Z. M.; He, H Y.; Wang, D. Y. Acta Phys. -Chim. Sin. 2021, 37, 2007016. [王木钦, 彭哲, 林欢, 李振东, 刘健, 任重民, 何海勇, 王德宇. 物理化学 学报, 2021, 37, 2007016.] doi: 10.3866/PKU.WHXB202007016

(13) Xu, W.; Wang, J.; Ding, F.; Chen, X.; Nasybulin, E.; Zhang, Y.; Zhang, J. G. Energy Environ. Sci. 2014, 7, 513. doi: $10.1039 / \mathrm{c} 3 \mathrm{ee} 40795 \mathrm{k}$

(14) Yu, X. R.; Ma, J.; Mou, C. B.; Cui, G. L. Acta Phys. -Chim. Sin. 2021, 37, 1912061. [虞金润, 马君, 牟春博, 崔光磊. 物理化学学 报, 2021, 37, 1912061.] doi: 10.3866/PKU.WHXB201912061

(15) Zhang, Q. Acta Phys. -Chim. Sin. 2017, 33, 1275. [张强. 物理化学 学报, 2017, 33, 1275.] doi: 10.3866/PKU.WHXB201705021

(16) Guo, Y.; Li, H.; Zhai, T. Adv. Mater. 2017, 29, 1700007. doi: 10.1002/adma.201700007

(17) Yin, Y. X.; Xin, S.; Guo, Y. G.; Wan, L. J. Angew. Chem. Int. Ed. 2013, 52, 13186. doi: 10.1002/anie.201304762

(18) Li, P.; Dong, X.; Li, C.; Liu, J.; Liu, Y.; Feng, W.; Wang, C.; Wang, Y.; Xia, Y. Angew. Chem. Int. Ed. 2019, 58, 2093. doi: 10.1002/anie.201813905

(19) Yoshio, M.; Wang, H.; Fukuda, K.; Hara, Y.; Adachi, Y. J. Electrochem. Soc. 2000, 147, 1245. doi: 10.1149/1.1393344

(20) Cheng, X. B.; Hou, T. Z.; Zhang, R.; Peng, H. J.; Zhao, C. Z.; Huang, J. Q.; Zhang, Q. Adv. Mater. 2016, 28, 2888. 
doi: $10.1002 /$ adma.201506124

(21) Lin, D.; Liu, Y.; Liang, Z.; Lee, H. W.; Sun, J.; Wang, H.; Yan, K.; Xie, J.; Cui, Y. Nat. Nanotechnol. 2016, 11, 626. doi: 10.1038/nnano.2016.32

(22) Liu, Y.; Lin, D.; Liang, Z.; Zhao, J.; Yan, K.; Cui, Y. Nat. Commun. 2016, 7, 10992. doi: 10.1038/ncomms 10992

(23) Zhang, R.; Chen, X. R.; Chen, X.; Cheng, X. B.; Zhang, X. Q.; Yan, C.; Zhang, Q. Angew. Chem. Int. Ed. 2017, 56, 7764. doi: $10.1002 /$ anie. 201702099

(24) Cheng, X. B.; Peng, H. J.; Huang, J. Q.; Zhang, R.; Zhao, C. Z.; Zhang, Q. ACS Nano 2015, 9, 6373. doi: 10.1021/acsnano.5b01990

(25) Zhang, R.; Cheng, X. B.; Zhao, C. Z.; Peng, H. J.; Shi, J. L.; Huang, J. Q.; Wang, J.; Wei, F.; Zhang, Q. Adv. Mater. 2016, 28, 2155. doi: 10.1002/adma.201504117

(26) Zhang, D.; Zhou, Y.; Liu, C.; Fan, S. Nanoscale 2016, 8, 11161. doi: $10.1039 / \mathrm{c} 6$ nr00465b

(27) Zhang, Y.; Liu, B.; Hitz, E.; Luo, W.; Yao, Y.; Li, Y.; Dai, J.; Chen, C.; Wang, Y.; Yang, C.; et al. Nano Res. 2017, 10, 1356. doi: $10.1007 / \mathrm{s} 12274-017-1461-2$

(28) Li, Q.; Zhu, S.; Lu, Y. Adv. Funct. Mater. 2017, 27, 1606422. doi: $10.1002 /$ adfm. 201606422

(29) Yang, C. P.; Yin, Y. X.; Zhang, S. F.; Li, N. W.; Guo, Y. G. Nat. Commun. 2015, 6, 8058. doi: 10.1038/ncomms9058

(30) Lin, D.; Liu, W.; Liu, Y.; Lee, H. R.; Hsu, P. C.; Liu, K.; Cui, Y. Nano Lett. 2016, 16, 459. doi: 10.1021/acs.nanolett.5b04117

(31) Murugan, R.; Thangadurai, V.; Weppner, W. Angew. Chem. Int. Ed. 2007, 46, 7778. doi: 10.1002/anie.200701144

(32) Zeng, X. X.; Yin, Y. X.; Li, N. W.; Du, W. C.; Guo, Y. G.; Wan, L. J. J. Am. Chem. Soc. 2016, 138, 15825. doi: 10.1021/jacs.6b10088

(33) Li, N. W.; Yin, Y. X.; Yang, C. P.; Guo, Y. G. Adv. Mater. 2016, 28, 1853. doi: 10.1002/adma.201504526

(34) Chen, H.; Pei, A.; Lin, D.; Xie, J.; Yang, A.; Xu, J.; Lin, K.; Wang, J.; Wang, H.; Shi, F.; et al. Adv. Energy Mater. 2019, 9, 1900858. doi: 10.1002/aenm.201900858

(35) Zhai, P.; Wei, Y.; Xiao, J.; Liu, W.; Zuo, J.; Gu, X.; Yang, W.; Cui, S.; Li, B.; Yang, S.; et al. Adv. Energy Mater. 2020, 10, 1903339. doi: 10.1002/aenm.201903339

(36) Lu, Y.; Gu, S.; Hong, X.; Rui, K.; Huang, X.; Jin, J.; Chen, C.; Yang, J.; Wen, Z. Energy Storage Mater. 2018, 11, 16 . doi: 10.1016/j.ensm.2017.09.007

(37) Chen, K.; Pathak, R.; Gurung, A.; Adhamash, E. A.; Bahrami, B.; He, Q.; Qiao, H.; Smirnova, A. L.; Wu, J. J.; Qiao, Q.; et al. Energy Storage Mater. 2019, 18, 389. doi: 10.1016/j.ensm.2019.02.006

(38) Li, Y.; Sun, Y.; Pei, A.; Chen, K.; Vailionis, A.; Li, Y.; Zheng, G.; Sun, J.; Cui, Y. ACS Cent. Sci. 2018, 4, 97. doi: $10.1021 /$ acscentsci.7b00480
(39) Ma, G.; Wen, Z.; Wu, M.; Shen, C.; Wang, Q.; Jin, J.; Wu, X. Chem. Commun. 2014, 50, 14209. doi: 10.1039/c4cc05535g

(40) Wu, M.; Wen, Z.; Liu, Y.; Wang, X.; Huang, L. J. Power Sources 2011, 196, 8091. doi: 10.1016/j.jpowsour.2011.05.035

(41) Lin, D.; Liu, Y.; Chen, W.; Zhou, G.; Liu, K.; Dunn, B.; Cui, Y. Nano Lett. 2017, 17, 3731. doi: 10.1021/acs.nanolett.7b01020

(42) Shen, X.; Li, Y.; Qian, T.; Liu, J.; Zhou, J.; Yan, C.; Goodenough, J. B. Nat. Commun. 2019, 10, 900. doi: 10.1038/s41467-019-08767-0

(43) Lang, J.; Long, Y.; Qu, J.; Luo, X.; Wei, H.; Huang, K.; Zhang, H.; Qi, L.; Zhang, Q.; Li, Z.; et al. Energy Storage Mater. 2019, 16, 85. doi: $10.1016 /$ j.ensm.2018.04.024

(44) Fan, L.; Zhuang, H. L.; Gao, L.; Lu, Y.; Archer, L. A. J. Mater. Chem. $A$ 2017, 5, 3483. doi: 10.1039/c6ta10204b

(45) Han, X.; Gong, Y.; Fu, K. K.; He, X.; Hitz, G. T.; Dai, J.; Pearse, A.; Liu, B.; Wang, H.; Rubloff, G. et al. Nat. Mater. 2017, 16, 572. doi: $10.1038 / \mathrm{nmat} 4821$

(46) Kozen, A. C.; Lin, C. F.; Pearse, A. J.; Schroeder, M. A.; Han, X. G.; Hu, L. B.; Lee, S. B.; Rubloff, G. W.; Noked, M. ACS Nano 2015, 9 , 5884. doi: 10.1021/acsnano.5b02166

(47) Lee, J. I.; Shin, M.; Hong, D.; Park, S. Adv. Energy Mater. 2019, 9 , 1803722. doi: 10.1002/aenm.201803722

(48) Cheng, X. B.; Zhao, C. Z.; Yao, Y. X.; Liu, H.; Zhang, Q. Chem 2019, 5, 74. doi: 10.1016/j.chempr.2018.12.002

(49) Li, N. W.; Shi, Y.; Yin, Y. X.; Zeng, X. X.; Li, J. Y.; Li, C. J.; Wan, L. J.; Wen, R.; Guo, Y. G. Angew. Chem. Int. Ed. 2018, 57, 1505. doi: 10.1002/anie.201710806

(50) Liu, K.; Pei, A.; Lee, H. R.; Kong, B.; Liu, N.; Lin, D.; Liu, Y.; Liu, C.; Hsu, P. C.; Bao, Z.; et al. J. Am. Chem. Soc. 2017, 139, 4815. doi: $10.1021 /$ jacs.6b13314

(51) Hu, Z.; Zhang, S.; Dong, S.; Li, W.; Li, H.; Cui, G.; Chen, L. Chem. Mater. 2017, 29, 4682. doi: 10.1021/acs.chemmater.7b00091

(52) Tu, Z.; Choudhury, S.; Zachman, M. J.; Wei, S.; Zhang, K.; Kourkoutis, L. F.; Archer, L. A. Joule 2017, 1, 394. doi: 10.1016/j.joule.2017.06.002

(53) Ma, G.; Wen, Z.; Wang, Q.; Shen, C.; Jin, J.; Wu, X. J. Mater. Chem. A 2014, 2, 19355. doi: $10.1039 / \mathrm{c} 4 \mathrm{ta} 04172 \mathrm{k}$

(54) Gao, Y.; Zhao, Y.; Li, Y. C.; Huang, Q.; Mallouk, T. E.; Wang, D. J. Am. Chem. Soc. 2017, 139, 15288. doi: 10.1021/jacs.7b06437

(55) Luo, J.; Fang, C. C.; Wu, N. L. Adv. Energy Mater. 2018, 8, 1701482. doi: $10.1002 /$ aenm. 201701482

(56) Sun, Y.; Zhao, Y.; Wang, J.; Liang, J.; Wang, C.; Sun, Q.; Lin, X.; Adair, K. R.; Luo, J.; Wang, D.; et al. Adv. Mater. 2019, 31, e1806541. doi: 10.1002/adma.201806541

(57) Liu, J.; Qian, T.; Wang, M.; Zhou, J.; Xu, N.; Yan, C. Nano Lett. 2018, 18, 4598. doi: 10.1021/acs.nanolett.8b01882

(58) Kang, D.; Sardar, S.; Zhang, R.; Noam, H.; Chen, J.; Ma, L.; Liang, 
W.; Shi, C.; Lemmon, J. P. Energy Storage Mater. 2020, 27, 69. doi: 10.1016/j.ensm.2020.01.020

(59) Xu, R.; Xiao, Y.; Zhang, R.; Cheng, X. B.; Zhao, C. Z.; Zhang, X. Q.; Yan, C.; Zhang, Q.; Huang, J. Q. Adv. Mater. 2019, 31, e1808392. doi: 10.1002/adma.201808392

(60) Yang, C.; Liu, B.; Jiang, F.; Zhang, Y.; Xie, H.; Hitz, E.; Hu, L. Nano Res. 2017, 10, 4256. doi: 10.1007/s12274-017-1498-2

(61) Liu, Y.; Lin, D.; Yuen, P. Y.; Liu, K.; Xie, J.; Dauskardt, R. H.; Cui, Y. Adv. Mater. 2017, 29, 1605531. doi: 10.1002/adma.201605531

(62) Kozen, A. C.; Lin, C. F.; Zhao, O.; Lee, S. B.; Rubloff, G. W.; Noked, M. Chem. Mater. 2017, 29, 6298. doi: 10.1021/acs.chemmater.7b01496

(63) Liu, F.; Xiao, Q.; Wu, H. B.; Shen, L.; Xu, D.; Cai, M.; Lu, Y. $A d v$. Energy Mater. 2018, 8, 1701744. doi: 10.1002/aenm.201701744

(64) Adair, K. R.; Zhao, C. T.; Banis, M. N.; Zhao, Y.; Li, R. Y.; Cai, M.; Sun, X. L. Angew. Chem. Int. Ed. 2019, 58, 15797. doi: 10.1002/anie.201907759

(65) Sun, C.; Huang, X.; Jin, J.; Lu, Y.; Wang, Q.; Yang, J.; Wen, Z. J. Power Sources 2018, 377, 36. doi: 10.1016/j.jpowsour.2017.11.063

(66) Xu, R.; Zhang, X. Q.; Cheng, X. B.; Peng, H. J.; Zhao, C. Z.; Yan, C.; Huang, J. Q. Adv. Funct. Mater. 2018, 28, 1705838. doi: $10.1002 /$ adfm. 201705838

(67) Li, S.; Fan, L.; Lu, Y. Energy Storage Mater. 2019, 18, 205. doi: 10.1016/j.ensm.2018.09.015

(68) Cheng, X. B.; Yan, C.; Chen, X.; Guan, C.; Huang, J. Q.; Peng, H. J.; Zhang, R.; Yang, S. T.; Zhang, Q. Chem 2017, 2, 258. doi: 10.1016/j.chempr.2017.01.003

(69) Liu, Q. C.; Xu, J. J.; Yuan, S.; Chang, Z. W.; Xu, D.; Yin, Y. B.; Li, L.; Zhong, H. X.; Jiang, Y. S.; Yan, J. M.; et al. Adv. Mater. 2015, 27, 5241. doi: 10.1002/adma.201501490

(70) Liu, S.; Xia, X.; Deng, S.; Xie, D.; Yao, Z.; Zhang, L.; Zhang, S.; Wang, X.; Tu, J. Adv. Mater. 2019, 31, e1806470. doi: 10.1002/adma.201806470

(71) Yan, K.; Lu, Z.; Lee, H. W.; Xiong, F.; Hsu, P. C.; Li, Y.; Zhao, J.; Chu, S.; Cui, Y. Nat. Energy 2016, 1, 16010. doi: $10.1038 /$ nenergy. 2016.10

(72) Liu, S.; Ma, Y.; Zhou, Z.; Lou, S.; Huo, H.; Zuo, P.; Wang, J.; Du, C.; Yin, G.; Gao, Y. Energy Storage Mater. 2020, 33, 423. doi: 10.1016/j.ensm.2020.08.007

(73) Liang, X.; Pang, Q.; Kochetkov, I. R.; Sempere, M. S.; Huang, H.; Sun, X.; Nazar, L. F. Nat. Energy 2017, 2, 17119. doi: 10.1038/nenergy.2017.119

(74) Jiang, Z.; Jin, L.; Han, Z.; Hu, W.; Zeng, Z.; Sun, Y.; Xie, J. Angew. Chem. Int. Ed. 2019, 58, 11374. doi: 10.1002/anie.201905712
(75) Ma, L.; Kim, M. S.; Archer, L. A. Chem. Mater. 2017, 29, 4181. doi: 10.1021/acs.chemmater.6b03687

(76) Tang, W.; Yin, X.; Kang, S.; Chen, Z.; Tian, B.; Teo, S. L.; Wang, X.; Chi, X.; Loh, K. P.; Lee, H. W.; et al. Adv. Mater. 2018, e1801745. doi: 10.1002/adma.201801745

(77) Hu, Z.; Liu, F.; Gao, J.; Zhou, W.; Huo, H.; Zhou, J.; Li, L. Adv. Funct. Mater. 2020, 30, 1907020. doi: 10.1002/adfm.201907020

(78) Liu, S.; Zhang, X.; Li, R.; Gao, L.; Luo, J. Energy Storage Mater. 2018, 14, 143. doi: 10.1016/j.ensm.2018.03.004

(79) Fu, K. K.; Gong, Y. H.; Liu, B. Y.; Zhu, Y. Z.; Xu, S. M.; Yao, Y. G.; Luo, W.; Wang, C. W.; Lacey, S. D.; Dai, J. Q.; et al. Sci. Adv. 2017, 3, e1601659. doi: 10.1126/sciadv.1601659

(80) Yan, C.; Cheng, X. B.; Yao, Y. X.; Shen, X.; Li, B. Q.; Li, W. J.; Zhang, R.; Huang, J. Q.; Li, H.; Zhang, Q. Adv. Mater. 2018, 30, 1804461. doi: 10.1002/adma.201804461

(81) Li, T.; Shi, P.; Zhang, R.; Liu, H.; Cheng, X. B.; Zhang, Q. Nano Res. 2019, 12, 2224. doi: 10.1007/s12274-019-2368-x

(82) Zheng, G.; Lee, S. W.; Liang, Z.; Lee, H. W.; Yan, K.; Yao, H.; Wang, H.; Li, W.; Chu, S.; Cui, Y. Nat. Nanotechnol. 2014, 9, 618. doi: 10.1038/nnano.2014.152

(83) Yan, J.; Yu, J.; Ding, B. Adv. Mater. 2018, 30, 1705105. doi: 10.1002/adma.201705105

(84) Yan, M.; Liang, J. Y.; Zuo, T. T.; Yin, Y. X.; Xin, S.; Tan, S. J.; Guo, Y. G.; Wan, L. J. Adv. Funct. Mater. 2020, 30, 1908047. doi: 10.1002/adfm.201908047

(85) Huo, H.; Chen, Y.; Li, R.; Zhao, N.; Luo, J.; da Silva, J. G. P.; Muecke, R.; Kaghazchi, P.; Guo, X.; Sun, X. Energy Environ. Sci. 2020, 13, 127. doi: 10.1039/c9ee01903k

(86) Yang, Q.; Li, W.; Dong, C.; Ma, Y.; Yin, Y.; Wu, Q.; Xu, Z.; Ma, W.; Fan, C.; Sun, K. J. Energy Chem. 2020, 42, 83. doi: 10.1016/j.jechem.2019.06.012

(87) Zhu, B.; Jin, Y.; Hu, X. Z.; Zheng, Q. H.; Zhang, S.; Wang, Q. J.; Zhu, J. Adv. Mater. 2017, 29, 1603755. doi: 10.1002/adma.201603755

(88) Li, Q.; Zeng, F. L.; Guan, Y. P.; Jin, Z. Q.; Huang, Y. Q.; Yao, M.; Wang, W. K.; Wang, A. B. Energy Storage Mater. 2018, 13, 151. doi: 10.1016/j.ensm.2018.01.002

(89) Luo, J.; Lee, R. C.; Jin, J. T.; Weng, Y. T.; Fang, C. C.; Wu, N. L. Chem. Commun. 2017, 53, 963. doi: 10.1039/c6cc09248a

(90) Yao, Y.; Zhao, X.; Razzaq, A. A.; Gu, Y.; Yuan, X.; Shah, R.; Lian, Y.; Lei, J.; Mu, Q.; Ma, Y.; et al. J. Mater. Chem. A 2019, 7, 12214. doi: $10.1039 / \mathrm{c} 9 \mathrm{ta} 03679 \mathrm{~b}$

(91) Jing, H. K.; Kong, L. L.; Liu, S.; Li, G. R.; Gao, X. P. J. Mater. Chem. A 2015, 3, 12213. doi: 10.1039/c5ta01490e 